\title{
Construção de significados e ambiguidades na supervisão de estágio em psicologia
}

\author{
Nádia Oliveira da Silva* (1) \\ Marina Assis Pinheiro \\ Candy Estelle Laurendon (1) \\ Universidade Federal de Pernambuco, Recife, PE, Brasil
}

\begin{abstract}
Resumo: Na formação de psicólogos, o tripé supervisão-estágio-ensino é fundamental para o desenvolvimento de competências profissionais. Todavia a relação estreita entre estas três esferas ocasiona, por vezes, uma compreensão nebulosa sobre a práxis concernente a cada um destes campos. À luz do dialogismo bakhtiniano e da intersubjetividade, este artigo visa a analisar a construção de significados sobre supervisão de estágio, por meio das ambiguidades que enlaçam esta atividade. Foi possível analisar que as ambiguidades permeadas pelo tripé formativo ocasionam tensões nas relações intersubjetivas, sendo balizadoras na construção de novos significados sobre a atividade de supervisão. Estes significados são tecidos pela negociação com as outridades que permeiam essa atividade formativa e pelo contexto em que são realizadas. Isto posto, estudos desta natureza propiciam uma compreensão mais ampla sobre conhecimentos teóricos/práticos concernentes ao campo da supervisão, o que pode ensejar a construção de estratégias facilitadoras na formação de psicólogos.
\end{abstract}

Palavras-chave: construção de significados, ambiguidades, dialogismo, intersubjetividade, supervisão de estágio em psicologia.

\section{Introdução}

A supervisão de estágio em psicologia clínica marca o momento de transição do graduando entre a teoria e o início na prática profissional, sendo ele convidado a articular essas duas modalidades de conhecimento visando ao aprimoramento de competências profissionais (Campos, 1999; Oliveira-Monteiro \& Nunes, 2008). Nesse sentido, trata-se de uma atividade fundamental para a formação de psicólogos, uma vez que favorece a construção e o desenvolvimento de importantes habilidades para o exercício do manejo psicoterapêutico na clínica.

Dada sua importância, espera-se que o supervisor de estágio tenha algumas competências básicas que viabilizem a formação profissional dos supervisionados, quais sejam: (i) o fomento da interlocução entre teoria estudada ao longo da graduação com a prática do estágio clínico; (ii) a garantia de que o grupo de supervisão possa aprender e desenvolver competências básicas para o exercício da clínica; e (iii) a promoção de boas relações entre o grupo, de modo que os supervisionados possam expor suas dificuldades e possíveis erros mediante a prática dos atendimentos clínicos (Barreto \& Barletta, 2010; Oliveira-Monteiro \& Nunes, 2008).

No tocante à literatura sobre a supervisão de estágio em psicologia, a maioria dos trabalhos encontrados diz respeito a relatos de experiências de profissionais acerca de suas práticas de supervisão

* Endereço para correspondência: nadiaoliveira.s92@gmail.com e, também, sobre modelos de supervisão assentados em diferentes abordagens psicoterápicas (Boris, 2008; Fernandes, Miyazaki, \& Silvares, 2015; Prebianchi \& Amatuzzi, 2000; Sousa \& Padovani, 2015). Além disso, a maioria desses trabalhos evidenciam a escassez de estudos realizados neste campo de atuação profissional e que ilustrem um modo de realizar a supervisão de estágio de maneira mais sistemática, em especial no que diz respeito aos modos de acompanhamento da formação do estagiário (Barreto \& Barletta, 2010; Rodrigues, 2007; Saraiva \& Nunes, 2007; Sei \& Paiva, 2011).

Com base no cenário apresentado, Silva (2019) realizou um estudo exploratório sobre a atividade profissional de supervisão de estágio clínico em psicologia, de modo a oferecer contribuições e maior entendimento a respeito de como esta prática formativa é construída e realizada. Em linhas gerais, encontrou-se uma pluralidade de modelos de supervisões marcados pelas trajetórias singulares de cada um dos profissionais que participaram do estudo e a influência que outras atividades laborais - como a clínica psicológica e a docência universitária - exercem na construção dessa práxis (aspecto este não aprofundado no estudo). Além disso, a conjuntura institucional em que essas práticas são exercidas demonstrou influenciar diretamente no modo como elas são construídas e praticadas pelos supervisores (Silva, 2019).

Assentado nesses resultados, este trabalho tem como objetivo ampliar a discussão tecida no estudo mencionado, ao propor uma reflexão sobre a construção de significados da prática de supervisão de 
estágio em psicologia clínica, através da ambiguidade de elementos que permeiam essa atividade, por exemplo, sua proximidade com outras atividades laborais, como a clínica psicológica e a docência universitária. Para este fim, serão utilizados como base para a discussão os dados de dois supervisores de estágio, obtidos no primeiro momento do estudo realizado por Silva (2019). A escolha desses dados será mais bem explicitada na seção de "Metodologia" deste artigo.

Além disso, a discussão proposta será respaldada na perspectiva dialógica e na intersubjetividade humana, tendo em vista que estes conceitos se pautam em processos de comunicação interativa, nos quais os sujeitos se constituem e se reconhecem como tal nas relações com o outro, que é singular em sua existência (Brait, 2005).

Acredita-se, por fim, que a análise proposta poderá oferecer elementos para compreender as ambiguidades que marcam esta atividade formativa e que, ao mesmo tempo, a torna singular.

\section{A atividade da supervisão em psicologia clínica}

A supervisão de estágio em psicologia clínica é primordial para a formação de psicólogos, uma vez que favorece o desenvolvimento de competências essenciais para atuação na clínica psicológica. Trata-se, pois, de uma atividade formativa que simboliza a passagem de um contexto teórico para um mais prático de atuação, e a articulação dessas duas esferas do conhecimento é um desafio constante vivenciado pelos estagiários para o aperfeiçoamento de competências profissionais (Campos, 1999; Oliveira-Monteiro \& Nunes, 2008).

No âmbito da psicologia clínica, o supervisor costuma ser um psicólogo mais experiente na psicoterapia e nos seus modos de intervenção, que, a partir da escuta ativa dos relatos de sessões dos atendimentos, orientará os estagiários sobre possíveis formas de manejo clínico dos casos (Moreira, 2003). Falender \& Shafranske (2004) alegam que o objetivo da supervisão em psicologia é facilitar o processo de aprendizagem dos conhecimentos concernentes à clínica psicológica, por meio da observação da atividade, de feedbacks, da (auto) avaliação dos supervisionados a partir de instruções e da resolução conjunta de situações desafiadoras que surgem no contexto de formação.

Além disso, espera-se que o supervisor tenha outros atributos para o exercício da atividade profissional. De acordo com Tavora (2002), supervisionar os atendimentos clínicos implica, ainda, em suscitar no grupo de supervisão reflexões acerca dos elementos subjetivos que os estagiários podem experienciar na relação terapêutica com seus clientes/pacientes. A partir dessa reflexão, os psicólogos em formação poderão distinguir os elementos pertencentes a si e ao sujeito sob acompanhamento psicoterápico, o que irá favorecer o desenvolvimento de competências para o exercício clínico como a escuta, por exemplo.
Apesar do ponto enfatizado, é importante considerar que, na formação de psicólogos clínicos, o supervisor de estágio também é incumbido pela preservação e pelo acolhimento das pessoas que estão sob acompanhamento dos seus estagiários, além de assegurar o desenvolvimento de competências básicas da clínica para o seu exercício de forma responsável e autônoma (Bastidas-Bilbao \& Velásquez, 2016).

Assim, é fundamental que o supervisor tenha habilidades específicas para gerenciar e manejar os grupos de supervisão. A maioria dos trabalhos realizados nessa área assegura que a qualidade da relação estabelecida entre supervisor-supervisionado propicia um ambiente de aprendizagem e desenvolvimento da atividade clínica de maneira mais significativa (Prebianchi \& Amatuzzi, 2000). Alguns autores, como Buys (1987) e Prebianchi \& Amatuzzi (2000), descrevem que essas relações favorecem ao futuro psicólogo reflexões a respeito dos aspectos teóricos e práticos experienciados na atividade clínica psicológica.

Dada a importância do vínculo construído no espaço da supervisão, é possível alegar que as relações formadas entre supervisor-supervisionado(s) são distintas das relações presentes em contexto de ensino formal (de sala de aula) entre os discentes e o professor. O processo de formação profissional e as práticas estabelecidas no espaço de supervisão são realizados por meio de relações que extrapolam as barreiras do ensino convencional (Oliveira-Monteiro \& Nunes, 2008). Trata-se, pois, de relações mais próximas possibilitadas pelo grupo de supervisão, que é bem menor comparando-se ao contexto de sala de aula, e essa característica possibilita que o supervisor realize um acompanhamento mais próximo dos processos de aprendizagem e desenvolvimento das competências profissionais dos estagiários.

Embora a supervisão em psicologia seja vista como uma atividade fundamental para a formação de psicólogos, são escassos os estudos realizados nesse campo de atuação. A maioria dos estudos encontrados trata de relatos de experiência feitos, geralmente, pelos próprios supervisores; além da descrição de instrumentos e técnicas baseados em abordagens psicoterápicas nas quais estes profissionais se apoiam em suas atividades (Boris, 2008; Prebianchi \& Amatuzzi, 2000; Sá, Azevedo Junior, \& Leite, 2010; Vieira, Bezerra, Pinheiro, \& Branco 2018).

Além do mais, muitos desses trabalhos apontam para a inexistência de uma maior organização e clareza sobre a atividade de supervisão em psicologia clínica, que possibilitasse a reflexão sobre a atividade formativa e profissional, a fim de salvaguardar uma formação eficiente para os graduandos em psicologia, por meio da aprendizagem e do desenvolvimento de competências básicas para o exercício da atividade como psicólogos clínicos (Barreto \& Barletta, 2010; Rodrigues, 2007; Saraiva \& Nunes, 2007; Sei \& Paiva, 2011). 


\section{Dialogismo bakhtiniano}

O dialogismo bakhtiniano é concebido como uma das bases componentes do discurso responsável pelo papel dinâmico dos sujeitos implicados nas múltiplas dimensões da relação entre eu-outro no plano da cultura, marcada pela interminabilidade histórica da cadeia de diálogos próprios ao tecido social (Bakhtin, 2000; Carvalho, 2014). As relações dialógicas são providas de sentido e firmadas entre enunciados da comunicação verbal estabelecidos entre o eu-outro em dinâmicas dialógicas instauradas historicamente pelos sujeitos (Bakhtin, 2000).

Apesar de se tratar de enunciados históricos, eles não são o reflexo ou entoação de algo já preexistente, muito menos de algo que está fora do sujeito, ou que lhe é dado nas relações, pois o enunciado sempre recria algo que não existia antes dele. Em outras linhas, para Bakhtin (2000), "o dado se transfigura no criado" (p. 348), e este criado provém da realidade e sentimentos que são idiossincráticos ao sujeito numa responsividade coautorada pelas mais diversas vozes sociais. À vista disso, o enunciado é considerado um ato singular que emerge numa atitude responsiva a outras vozes e que nunca se repete, pois sempre se remodela conforme o contexto em que é enunciado (Faraco \& Shafranske, 2009). Não existe neutralidade na enunciação, pois ela está situada num campo ideológico proveniente de um dado contexto cultural com significados e valores particulares (Bakhtin, 2000).

A partir dessas considerações, "Compreender a enunciação de outrem significa orientar-se em relação a ela, encontrar o seu lugar adequado no contexto correspondente" (Bakhtin, 2006 p. 135). E, nesse sentido, o discurso é construído por meio do outro que viabiliza a construção de processos comunicativos interacionais, os quais possibilitam a constituição do sujeito ao reconhecer seu $e u$ a partir da imagem que o outro faz de si (Barros, 2003).

A palavra, para Bakhtin (2000), é interindividual, uma vez que tudo que é expresso se encontra externo ao que enuncia, não lhe pertencendo de forma exclusiva, pois "o autor (o locutor) tem seus direitos imprescritíveis sobre a palavra, mas também o ouvinte tem seus direitos, e todos aqueles cujas vozes soam na palavra têm seus direitos" (Bakhtin, 2000, p. 350). Essa característica possibilita que a palavra não se cristalize e se separe do diálogo, pois não conhecemos tudo que ela pode representar nas relações. No contexto das interações dialógicas bakhtinianas, a situação presente representa o contexto histórico no qual um ato responde a outros vários atos e, por isso, estas interações também estabelecem significados por meio de eventos passados, carregando uma grande variedade de vozes que ecoam sentidos construídos historicamente (Carvalho, 2014).

Nessa perspectiva, a construção de significados se dá pelas trocas discursivas que estão cercadas por uma arena de vozes provenientes de um espaço histórico-social
(Bakhtin, 2000). Os significados surgirão por intermédio da refração particular e única da responsividade do ator na cadeia histórica do diálogo que, por isso, será percebido de maneira diferente por outro sujeito que se coloque em seu lugar. Desse modo, as relações dialógicas são uma imprescindibilidade para que os indivíduos possam apreender enunciados, negociar e construir significados que lhe sejam possíveis em dado contexto social.

\section{Intersubjetividade humana nas relações}

Uma vez que se parte do pressuposto de que a atividade do supervisor de estágio é tecida por meio da negociação e da construção de significados principalmente na díade supervisor-supervisionado(s) -, a perspectiva construtivista semiótico-cultural também pode ser um importante aporte teórico no fundamento da discussão aqui proposta. Isso tendo em vista que tal perspectiva tem se debruçado sobre o tema da intersubjetividade, por meio do enfoque em questões concernentes aos processos subjetivos e à mediação social simbólica presente no desenvolvimento sociocultural humano. Além disso, e de acordo com Simão (2010), o construtivismo semiótico-cultural salienta o paradoxo da indissociabilidade/dissociabilidade que estão presentes de forma simultânea na diferenciação entre o eu e outro, por intermédio de processos de ordem cognitivoafetiva. Trata-se, pois, de processos que se exteriorizam e constroem o ambiente sociocultural, permitindo ao mesmo tempo em que os sujeitos se reconstruam na relação dialógica polifônica com os outros ou na multiplicidade de vozes de si mesmo, constituindo-se como selves (Simão, 2005, 2010).

Ainda nesta perspectiva teórica, Valsiner (1998) concebe a intersubjetividade como um domínio temporário de significados partilhados na relação entre duas ou mais pessoas, ou em distintos níveis de semiotização nesta mesma pessoa, permitindo que o sujeito transforme seus sistemas semióticos por meio de negociações simbólicas na relação consigo ou com os outros.

Os sistemas semióticos são caracterizados por este mesmo autor como fronteiras que atuam na (re) organização das experiências idiossincráticas fortuitas, e que são características intrínsecas a condição humana. Assim, essas fronteiras operam de modo a orientar as ações singulares do sujeito e as demandas que surgem do contexto social (Simão, 2005, 2010).

Nesse sentido, é por intermédio das relações intersubjetivas que se compartilham e negociam os significados que podem ou não transformar as significações da experiência subjetiva. É por essa perspectiva que Valsiner e Van Der Veer (2000) e Valsiner (2003) caracterizam a intersubjetividade como uma ocorrência temporária, dinâmica e interativa que necessita ser constantemente colocada e recolocada na comunicação. A intersubjetividade é, pois, um metaprocesso reflexível que leva o sentido pessoal da 
atividade dialógica à sua criação, configuração e mudança (Valsiner, 1998).

As relações intersubjetivas, como mencionado, são marcadas por uma arena de significações compartilhadas e negociadas, de maneira que se possa entrar num consenso que é balizador das interações simbólicas provenientes da própria cultura. Não obstante, esse consenso nunca é total, tratando-se de quase uma ilusão necessária às trocas comunicativas. Dessa forma, quando o consenso nestas relações se torna longínquo ou mesmo utópico, o indivíduo se vê numa posição de redirecionar suas ações nessa relação, imprimindo-lhe sua autonomia junto ao outro em seu processo de desenvolvimento (Simão, 2010)

\section{Ambiguidades nas relações intersubjetivas}

A construção do mundo subjetivo-cultural, segundo Valsiner (1998), é um processo causador de tensões que podem emergir nas relações intersubjetivas ou em cada pessoa mesma (tensão intrassubjetiva); e a tentativa de aplacar essas tensões pode fomentar a construção de novos significados. Assim, as tensões podem emergir por intermédio de oposições, discordâncias geradas no diálogo, ocasionadas pelas distintas elaborações construídas pelos indivíduos envolvidos na relação intersubjetiva e que inviabilizam as trocas e o consenso entre eu-outro (Simão, 2010).

Outro motivo gerador de tensão diz respeito à ideia alimentada pela ilusão de que é possível o entendimento de tudo que o falante dirige ao ouvinte na relação. Para Valsiner (1998), o "desencontro" de proposições de temas enunciados no diálogo comunicativo pode ensejar a reorganização dos argumentos de um interlocutor com relação a outro.

Não obstante, é preciso compreender que o uso da palavra vem munido da possibilidade de se fazer entender na relação ou não (Rommetveit, 1976). Para Bakhtin (2000), há uma busca ativa pelo sujeito em se fazer entender pelo outro e de compreendê-lo na relação, travando-se uma "luta dialógica".

Isto posto, a ambiguidade de sentidos se dá na relação dialógica contextual que propicia o uso da multiplicidade de significados existentes das palavras que se encontram em aberto fora dessa relação. Os significados das palavras são alterados conforme o contexto onde são empregadas, de maneira que a ambiguidade oscila constantemente no diálogo na busca da intersubjetividade; assim, o significado da palavra é constantemente um potencial que se remodela no momento do diálogo (Simão, 2010).

A descentralização das relações intersubjetivas representa a abertura para com o outro, na confiança de que ele esteja centrado em nos compreender na relação, e na disponibilidade interna de buscar que este outro nos compreenda e que nós o possamos compreender, para que assim se instaure a negociação e construção de significados dialógicos (Simão, 2010).
Para Marková (2006a; 2006b), o diálogo presente nas relações dialógicas, de antemão, possui natureza primordial que diz respeito ao fato de que quem fala não sabe inicialmente como deve expressar suas ideias ao outro, e muito menos sabe como ele irá entender ou reagir ao falado e, por isso, só tomará conhecimento sobre sua fala a partir da reação do outro diante do que foi enunciado. Assim, a reflexão sobre a comunicação eu-outro como construção dialógica implica em concebê-la como uma ocorrência que não se dá apenas a partir de um ponto de vista, mas também do ponto de vista do outro que tece construções sobre o ponto de vista em si (Simão, 2010).

Nas relações dialógicas, as pessoas envolvidas apresentam características únicas e, dada a natureza temporal dessas relações, os indivíduos são levados a reconstruir sua individualização diante dos novos diálogos que se instauram na relação (Simão, 2010). E é neste ciclo que os significados são sempre negociados e transformados.

A transformação dos significados, por outro lado, é ocasionada pelas interpretações construídas pelo sujeito sobre o mundo, sendo, pois, refrações idiossincráticas de um sujeito enunciante que escapa do habitual para lançar-se ao novo, por meio de interpretações singulares que realiza sobre o mundo (Tápias-Oliveira, Kleiman, \& Matencio, 2005). O conceito de refração aqui utilizado tem base na caracterização realizada por Faraco e Shafranske (2009), que afirmam que refratar diz respeito à construção sócio-histórica de interpretações realizadas por sujeitos sobre o mundo, por meio da multiplicidade de experiências intersubjetivas que também tornam os signos polissêmicos. Considerando sua natureza, os atos refrativos participam da transfiguração das crenças concernentes a esse sujeito (Severo, 2007).

\section{METODOLOGIA}

A análise e a discussão deste artigo tiveram base num recorte dos dados obtidos no estudo de Silva (2019), sendo utilizadas duas entrevistas sobre a trajetória de vida profissional de supervisores de estágio em psicologia.

Em linhas gerais, a entrevista se fundamenta na abordagem autobiográfica de Josso (2007), que é empregada com a finalidade de analisar as perspectivas de vida e os recursos relacionados às experiências subjetivas do participante. Na referida pesquisa, esse instrumento foi usado com o propósito de compreender, a partir do relato livre dos participantes do estudo, suas respectivas formações profissionais, desde o período da graduação até o momento em que passaram a exercer a atividade como supervisores de estágio na clínica.

De modo geral, a escolha das entrevistas se deu por elas viabilizarem maior compreensão sobre a produção de significados relativos à atividade de supervisão, uma vez que a trajetória de vida profissional retrata a concepção dos profissionais sobre como se tornaram supervisores de estágio. 
À vista disto, os dois supervisores de estágio escolhidos para este estudo atuam em instituições distintas situadas na região metropolitana do Recife. Miguel (nome fictício) trabalha como psicólogo numa instituição pública de saúde que recebe estudantes de psicologia para a realização do estágio curricular, que acontece no último ano da graduação em psicologia. Além disso, tem doze anos de formação como psicólogo e há três anos atua como supervisor de estágio em psicologia na instituição em que trabalha. Antônio (nome fictício) atua como supervisor de estágio há 23 anos no serviço-escola de psicologia de uma instituição privada, e é formado há 26 anos. Ademais, trabalha como psicólogo clínico em consultório particular, assim como Miguel.

Nas entrevistas dos profissionais supracitados, foram analisadas as passagens de fala que apresentassem pontos de tensão que demarcassem ambiguidades concernentes às suas respectivas práticas profissionais como supervisores de estágio, conforme apresentado no corpo teórico deste trabalho. Por meio desses pontos de tensão, exploraram-se as outridades que dialogam com esses profissionais na construção intersubjetiva de suas práticas como supervisores de estágio de modo singular.

\section{RESULTADOS E DISCUSSÃO}

Com base na análise das entrevistas dos profissionais escolhidos para este estudo, foi possível analisar que, em sua trajetória, houve motivações distintas que os levaram a exercer a atividade de supervisão de estágio. Tais motivações mostram terem sido instauradas a partir do contexto institucional no qual tais práticas são exercidas, no contexto deste estudo, o serviço-escola e a instituição de saúde que oferta a atividade de estágio.

Dessa maneira, um dos supervisores passou a atuar nesse campo a partir de um convite apresentado por uma profissional ligada diretamente à sua formação como psicólogo, como é possível constar neste trecho: "há dois anos formado, dois anos e alguma coisa assim, ela [sua supervisora] disse: 'Você quer ser supervisor em tal instituição de ensino?' . . . então a minha supervisora me convidou, e ai que tudo começou em termos de ser supervisor" (Antônio).

Nesse fragmento discursivo, a supervisora do profissional relata uma outridade fundamental para o ingresso na atividade de supervisão. Em outras palavras, trata-se de uma relação intersubjetiva que mostra ser formada por um sujeito iniciante nessa prática e um sujeito mais experiente na atividade de supervisão, sendo, pois, um marcador importante para a aprendizagem e construção da práxis, como pode ser observado no enunciado abaixo:

E como é que eu aprendi a fazer supervisão?! Na prática! Primeiro assim, a minha grande referência, como eu lhe falei, foi a [nome da sua supervisora], o modo como ela lidava com a questão da supervisão, não é?! Eu fui compreendendo o que é importante ser trabalhado em uma supervisão, qual é o papel do supervisor no trabalho de supervisão, não é?! Porque a gente não está atendendo diretamente aos clientes, né?! É aquela ação mesma com o supervisionando que vai trazendo os elementos para a supervisão.... $\dot{E}$, ajudar essa pessoa supervisionanda a... des... não é nem descobrir, mas é desenvolver o potencial terapêutico que ela pode desenvolver! . . a minha aprendizagem de supervisão foi muito experiencial, na relação com a minha primeira supervisora e na relação com os meus supervisionandos hoje. (Antônio)

Nesse enunciado, a experiência do profissional junto à sua supervisora se mostra marcada pela aprendizagem gerada no campo intersubjetivo da relação. $O$ destaque ao que é significado na refração singular do participante como experiencial indica um campo afetivo-semiótico único e que impacta a relação do participante com seus supervisionados, como uma outridade internalizada e significativa para seu campo de ação.

Por outro lado, Miguel traz em sua narrativa uma motivação distinta que o leva a se tornar supervisor de estágio. As funções que desempenha na instituição poderiam levá-lo a lidar com os fenômenos desse espaço de maneira mais parcial. Nesse sentido, mostra procurar um ponto de tensão em sua atividade - corporificada pelos questionamentos que os estagiários poderiam trazer sobre a prática realizada na instituição. Assim, é possível depreender que a idealização de um ambiente formativo na instituição que Miguel atua seria balizadora na construção de novas práxis nesse espaço, por meio dos pontos de tensão ocasionados pelos questionamentos trazidos pelos estagiários, sendo eles, por sua vez, uma outridade que não cessa de levantar questões próprias ao diálogo intersubjetivo:

Eu começo a me preocupar com o fato de que o [instituição que trabalha] está muito unilateral, está muito parcial com relação às minhas perspectivas de ver os fenômenos, ver as coisas, .. . e a minha preocupação é de que assim, eu podia estar incorrendo em muitos perigos de não ver uma série de coisas por estar aqui como coordenador e psicólogo do serviço, e aí achei que a possibilidade de ter estudantes aqui questionando tudo o tempo todo iria favorecer muito o serviço e a minha escuta.... comecei acolhendo duas estudantes, depois três, e são experiências fantásticas! Maravilhosas! De estar sempre envolvido com questões de base, questões fundamentais, questões que, a rigor, todo mundo acha que já estão resolvidas, né?! Que você parte disso pra não... a gente está sempre envolvido com as questões fundamentais, e isso é ótimo! . . essa experiência de ter pessoas críticas, perguntando sobre como o trabalho acontece, porque acontece assim, e podendo bulir, mexer na forma como a gente constrói as coisas 
aqui e, a partir de então, construir junto, é muito importante pra mim. (Miguel)

À vista das experiências abordadas de Miguel e Antônio, é possível notar que há elementos inerentes ao contexto institucional responsáveis pelo ingresso desses profissionais na atividade de supervisão. Tais elementos, sobretudo, dizem respeito às experiências idiossincráticas dos sujeitos entrevistados e provêm de relações intersubjetivas de naturezas diversas, sendo fundamentais para a construção da supervisão. A construção dessa práxis formativa ocorre por intermédio da produção de significados únicos a essa atividade, que se transformam conforme as relações e o contexto social no qual a atividade é desempenhada. A exemplo dessa afirmação, é possível observar que o final do enunciado anterior (Miguel) ilustra o espaço da supervisão como mobilizador de inquietações a respeito da prática do estágio, sendo, portanto, a reflexão e a criticidade marcas desse processo formativo.

Isto posto, tanto a trajetória de vida profissional como a instituição na qual a prática da supervisão é desempenhada performam as atividade desses supervisores, tendo em vista que eles refratam o sentido do "fazer do supervisor" por meio de suas experiências provindas tanto de suas formações como do próprio contexto onde atuam.

Além disso, e ao partir duma perspectiva bakhtiniana, é possível compreender as trajetórias de formação desses supervisores como uma construção de significados instaurada por enunciações da comunicação verbal entre eu-outro. As enunciações são atos singulares, providos da realidade, de sentimentos, e se remodela conforme o contexto. Dessa maneira, os enunciados presentes nas relações sempre são provenientes de determinado contexto cultural com significados e valores únicos (Bakhtin, 2000).

A natureza idiossincrática desses valores e significados advindos das outridades presentes nas relações intersubjetivas dão margem à existência de ambiguidades nessas relações, que podem ser negociadas verbalmente (Simão, 2005). Dada a relevância dessas tensões para construção de significados, analisaram-se, no discurso dos supervisores, as implicações das relações intersubjetivas nos respectivos contextos laborais para a construção da atividade de supervisão. Observou-se que a relação com os supervisionados e com outros profissionais da instituição é importante para a construção dessa atividade. No exemplo a seguir, é possível analisar como a dinâmica do grupo e o modo como as relações estão estabelecidas nesse espaço podem ser promotoras de conhecimento sobre a prática clínica e o campo da supervisão:

Eu considero o grupo de supervisão, mesmo ainda estudantes, como colegas de trabalho! Eu sempre falo grupos de trabalho no qual eu tenho uma função pela minha experiência, pela minha... pelo meu papel institucional, eu tenho uma função, mas ali nós somos, de algum modo, estamos ali para nos desenvolvermos, eu com a minha experiência um pouquinho mais. Mas quanto eu aprendo com os estagiários! E muito! Aprendo demais com eles! . . . Todos somos cossupervisores uns dos outros! Então, para que todo mundo também se sinta à vontade para estar contribuindo com uma ampliação, com o desenvolvimento do outro colega. (Antônio)

Analisa-se, no enunciado, que a dinâmica oriunda desse grupo diz respeito a relações que operam de modo mais horizontalizado, uma vez que seu modo de funcionamento é descrito como uma cossupervisão das situações clínicas, sendo, pois, significativas para a aprendizagem de Antônio, uma vez que são causadoras de tensões e ambiguidades. Nesse sentido, a horizontalidade referida encampa um processo de diminuição das assimetrias e corresponsabilização dos participantes no percurso formativo, ali onde as alteridades potenciais da relação supervisor-supervisionado irrompem. Então, por esse viés, a ambiguidade se apresenta na duplicidade de aprendiz e colega na compreensão do supervisor sobre o supervisionado, entre o estudante e o profissional em processo de tornar-se.

Miguel traz uma narrativa semelhante sobre a dinâmica do grupo de supervisão, indo mais além ao abordar, em seu discurso, as tensões advindas da experiência clínica dos estagiários e demais profissionais da instituição, tratando-se de uma condição fundamental para a construção do espaço de supervisão onde trabalha:

Têm surgido tantas coisas desse espaço [de atendimento ludoterápico no qual trabalha], dessas escutas, dessas experiências, desses colegas, seja dos colegas que estão no quarto periodo, seja dos outros colegas, assistentes sociais ou médicos que também brincam aqui, gente com trinta anos de experiência que começam. Eé tudo tão rico que a gente precisou fazer um espaço de supervisão! Pra que a gente possa falar sobre o que a gente "tá" vivendo ali e construir coisas, escrever e pensar. (Miguel)

Nesse enunciado, o espaço de supervisão é descrito como um ambiente que propicia a negociação de significados das experiências vivenciadas por estes sujeitos no contexto da clínica. Isto, tendo em vista que, em sua natureza, as relações intersubjetivas - provenientes desse espaço formativo ocasionam tensões e, consequentemente, transformações no campo da ação simbólica dos sujeitos envolvidos, sendo uma experiência individualmente construída. As tensões podem ser ocasionadas pelas assimetrias que surgem na relação dialógica, originadas pelas diferentes elaborações construídas pelos sujeitos envoltos nessa relação (Simão, 2010), estando presentes, portanto, nos enunciados dos dois supervisores deste estudo.

Em outras palavras, as assimetrias referidas dizem respeito a níveis distintos de semiotização (Valsiner, 
1998) representados pelas outridades envolvidas nessas relações, sendo algumas delas figuradas na atividade de supervisão de estágio nos papéis do supervisor, dos estagiários e formadores/docentes, pacientes/clientes etc. Nessas complexas redes de significados, cada profissional pode transformar seus sistemas de significação/refração singular a partir das negociações simbólicas com as outridades envolvidas na supervisão ou consigo mesmo (ao estar envolto por uma multiplicidade de vozes relativas à prática de supervisão), dando um caráter singular à atividade exercida por cada profissional.

Nesse sentido, outras funções laborais assumidas por estes profissionais - como a clínica psicológica e a docência universitária - também podem ocasionar ambiguidades mediante a prática da supervisão, uma vez que são atividades que têm relação muito estreita com esse campo. A experiência na clínica, por exemplo, é condição sine qua non para a prática de supervisão. Por outro lado, há uma discussão na literatura sobre as aproximações entre as atividades do supervisor e do professor e no que, possivelmente, elas se diferem (Oliveira-Monteiro \& Nunes, 2008).

Partindo dessas questões, perguntou-se aos profissionais, ao final da entrevista, sobre a trajetória de vida profissional e como eles compreendiam a diferença entre os três campos de atuação citados, sendo uma das respostas a seguinte:

O modo como eu sou convocado na sala de aula, não é?! No sentido da docência, é diferente do modo como eu sou convocado no espaço de supervisão. Porque, é... e também do espaço da clínica. São práticas da psicologia, mas são práticas diferentes que exigem de mim determinados posicionamentos que são pertinentes a cada situação dessa . . então, claro que esses vários papéis constituem, né?! Me tornam um profissional melhor, me tornam terapeuta melhor, me torna um supervisor melhor, tudo isso contribui para esse desenvolvimento como um todo. (Antônio)

No enunciado, a distinção realizada por Antônio sobre o campo da docência, da clínica e da supervisão mostra refletir uma clareza do profissional a respeito de como estas outridades dialogam, a fim de negociarem e construírem significados sobre cada uma dessas áreas de atuação. Na medida em que o supervisor está envolvido na relação com estes distintos papéis laborais e com os sujeitos que coautoram essas relações, há um esforço contínuo para que possam ser compreendidos uns pelos outros (Bakhtin, 2000).

Nesse processo, pode haver tensões geradas por diferentes elaborações construídas no diálogo pelos sujeitos envolvidos nessas relações, sendo, pois, fundamental para a distinção desses campos. A exemplo disso, o fragmento discursivo a seguir ilustra a ambiguidade referente ao papel do supervisor e do docente no espaço da supervisão:
Eu estava dando... cheguei a dar aula durante algum tempo na [nome da instituição de ensino], uma experiência fantástica! Eu gosto muito desse encontro, que não é um encontro de eu chegar lá e apresentar um conhecimento pronto e acabado, mas de poder estimular pessoas a pensarem, criticarem, a correrem atrás de coisas e de estudar, de ler, pronto! Mas ai acabou que a clínica, que é o que me fascina, que é o que eu gosto mais, acabou tomando conta desses horários que eu tinha como professor, e eu acho ótimo! E aqui é engraçado, porque as pessoas que vêm pra cá, os alunos vêm pra cá esperando encontrar um professor nesse sentido, né?! De conhecimento e tal, e acabam encontrando um supervisor e um analista. E não encontram necessariamente respostas, encontram uma complexificação de suas perguntas! (Miguel)

Nesse trecho, Miguel mostra que a diferenciação da figura do professor de um contexto de sala de aula se dá a partir dos papéis que assume nesse espaço como supervisor e analista, podendo ser afirmados, portanto, pelo ambiente institucional. Todavia a didática usada na formação dos estagiários mostra ser um reflexo de sua atuação na docência, pois, ao ilustrar sua experiência nesses dois papéis, mostra uma postura de incitar nos sujeitos uma postura mais reflexiva e crítica. Com base no fragmento discursivo apresentado, o profissional menciona que gosta de "estimular pessoas a pensarem, criticarem", ao se referir à sua experiência docente, ao passo que, na supervisão, atesta que os estagiários "encontram uma complexificação de suas perguntas". Nesse sentido, Miguel demonstra buscar um distanciamento da didática de ensino mais convencional, baseada na transmissão de conhecimentos centrada na figura do docente.

Por outro lado, também é possível que haja tensões ocasionadas pelas demandas dos casos clínicos trabalhados em supervisão versus as demandas pessoais dos estagiários, como abordado por Antônio:

Às vezes, a supervisão, ela não é grupo terapêutico, mas às vezes, por conta dessa proximidade, as pessoas trazem coisas pessoais. Claro que eu não vou trabalhar isso, mas fica como um espaço, né?! Porque às vezes as coisas pessoais, elas atrapalham e muito no desenvolvimento daquela pessoa junto àquele cliente, né?! Então a gente não trabalha, mas as pessoas começam a falar e eu só dou um toque: "Olhe! Preste atenção nisso! Preste atenção naquilo! Trabalhe isso no teu processo pessoal". (Antônio)

Neste exemplo, a ambiguidade instaurada diz respeito às atividades laborais que são diretamente atreladas à prática de supervisão, como a supervisão e a clínica psicológica, apresentadas anteriormente neste trabalho. No entanto Antônio mostra identificar os pontos limítrofes das duas atividades, mostrando ser um fator fundamental em sua performance formativa. 
Nesse sentido, é possível considerar que os distintos e momentâneos papéis laborais assumidos por estes profissionais tornam as experiências complementares nesse campo e, ao mesmo tempo, antagônicas. Isso tendo em vista que tais papéis dizem respeito a campos simbólicos que geram atos narrativos a partir da negociação de significados, responsáveis por mobilizar, transmitir, construir e ressignificar a experiência (Simão, 2005, 2010).

Além do mais, dada situação pode representar o contexto histórico cultural em que um ato é endereçado para outros atos e, por esse motivo, as construções de significados de tais interações também é provida de circunstâncias passadas, carregando uma multiplicidade de vozes que ressoam esses sentidos históricos (Carvalho, 2014).

\section{À GUISA DE CONCLUSÃO}

Este trabalho buscou expandir os estudos realizados por Silva (2019) ao propor uma reflexão sobre a construção de significados da prática de supervisão de estágio em psicologia clínica, a partir das ambiguidades que permeiam esta atividade. A noção de ambiguidade, neste estudo, parte da perspectiva de que a construção subjetiva-cultural do mundo se trata de um processo causador de tensões emergentes nas relações intersubjetivas (Valsiner, 1998). Com este intuito, utilizou-se um recorte dos resultados obtidos na primeira fase do estudo de Silva (2019), que foram analisados a partir dos conceitos de ambiguidade e intersubjetividade.

De modo geral, a multiplicidade idiossincrática e a dimensão sociocultural de aspectos envoltos na construção da supervisão tornam a atividade singular. Dentro dessa multiplicidade, é possível observar outridades que se encontram próximas à atividade de supervisão, quais sejam, a prática clínica psicológica e a docência universitária. Outro elemento que evidencia as ambiguidades presentes na construção da atividade de supervisão diz respeito ao contexto no qual elas são desempenhadas, a exemplo deste estudo, o contexto de serviço-escola e da instituição pública de saúde dos dois supervisores, respectivamente.

A multiplicidade de aspectos supracitados contribui para que a atividade da supervisão ainda seja um campo nebuloso. Isso gera maior indeterminação sobre a atividade, dando margem a uma negociação de significados mais intensa à supervisão de estágio.

De maneira mais objetiva, a entrevista sobre a trajetória de vida profissional oportunizou tal negociação, uma vez que os profissionais foram conduzidos a descrever sobre como se tornaram supervisores de estágio e a diferenciar as atividades laborais que desempenham em conjunto com a prática da supervisão.

Isto posto, a compreensão dos significados construídos pelos supervisores diante de suas práticas de atuação pode ser um caminho que viabiliza maior entendimento sobre os elementos teóricos e práticos concernentes a essa atividade, possibilitando, consecutivamente, a construção de estratégias que fomentem a formação profissional para psicólogos de maneira mais eficaz e abrangente.

Por outro lado, é possível anunciar que este estudo mostra uma possibilidade de ampliar horizontes teóricos, ao se basear em importantes conceitos da psicologia cultural semiótica - a saber, o dialogismo, ambiguidades e a intersubjetividade - para possibilitar a compreensão sobre a construção de significados numa atividade laboral; podendo, assim, ser usada como referencial teórico para a exploração de outras atividades laborais.

\title{
Construction of meanings and ambiguities in the context of internship supervision in psychology
}

\begin{abstract}
When training psychologists, the supervision-internship-teaching tripod is essential for the development of professional skills. However, the close relationship between these three spheres sometimes leads to a nebulous understanding of the praxis concerning each of these fields. In the light of Bakhtinian dialogism and intersubjectivity, this article analyzes the construction of meanings about internship supervision by verifying the ambiguities related to this activity. The ambiguities grounded on the formative tripod were shown to lead to tensions in intersubjective relations and served as basis to construct new meanings about the supervision activity. These meanings are built through negotiation with other identities that permeate this training activity and the context in which they are carried out. Therefore, studies of this nature provide a broader understanding of theoretical/practical knowledge concerning the zone of supervision, which in turn can lead to the construction of facilitating strategies in the training of psychologists.
\end{abstract}

Keywords: construction of meanings, ambiguities, dialogism, intersubjectivity, supervision of internship in psychology.

\section{Construction de signifiés et ambigüités dans la supervision de stages en psychologie}

Résumé: La formation de psychologues implique le triplet supervision-stage-enseignement, qui est fondamental pour le développement de compétences professionnelles. Mais, le rapport étroit entre ces trois sphères engendre parfois une compréhension floue de la praxis concernant chacun de ces champs. A partir du dialogisme bakhtinien et de l'intersubjectivité, 
le présent article a pour objectif d'analyser la construction de signifiés sur la supervision de stages, à travers des ambigüités qui entourne cette activité. Ainsi, les ambigüités qui traversent ce triplet formatif provoquent des tensions dans les rapports intersubjectifs et balisent la construction de nouveaux signifiés concernant l'activité de supervision. Ces signifiés sont établis à partir de la négociation des altérités qui traversent cette activité formative et du contexte dans lequel elles se réalisent. De tels travaux permettent une compréhension plus élargit sur les connaissances théoriques/pratiques du champ de la supervision, ce qui peut favoriser la construction des stratégies facilitatrices dans la formation de psychologues.

Mots-clés : construction de signifiés, ambigüités, dialogisme, intersubjectivité, supervision de stages en psychologie.

\section{Construcción de significados y ambigüedades en la supervisión de las prácticas en psicología}

Resumen: En la formación de psicólogos, el trípode de supervisión-prácticas-enseñanza es fundamental para el desarrollo de habilidades profesionales. Sin embargo, la estrecha relación entre estas tres esferas a veces conduce a una comprensión nebulosa de la praxis con respecto a cada uno de los campos antes mencionados. A la luz del diálogo de Bakhtin y la intersubjetividad, este artículo tiene como objetivo analizar la construcción de significados sobre la supervisión de prácticas, por medio de las ambigüedades que vinculan esta actividad. Las ambigüedades permeadas por el trípode formativo producen tensiones en las relaciones intersubjetivas, siendo faros en la construcción de nuevos significados sobre la actividad de supervisión. Estos significados se tejen por medio de la negociación con los demás que impregnan esta actividad de capacitación y el contexto en el que se lleva a cabo. Dicho esto, los estudios de esta naturaleza proporcionan una comprensión más amplia del conocimiento teórico-práctico sobre el campo de la supervisión, lo que puede conducir a la construcción de estrategias facilitadoras en la formación de psicólogos.

Palabras clave: construcción de significados, ambigüedades, dialogismo, intersubjetividad, supervisión de prácticas en psicología.

\section{Referências}

Bakhtin, M. (2000). Estética da criação verbal (3a ed.). São Paulo, SP: Martins Fontes.

Bakhtin, M. (2006). Marxismo e filosofia da linguagem (12a ed.). São Paulo, SP: Hucitec.

Barreto, M. C., \& Barletta, J. B. (2010). A supervisão de estágio em psicologia clínica sob as óticas do supervisor e do supervisionando. Caderno de Graduação: Ciências Biológicas e da Saúde, 12(12), 183-202. Recuperado de https://bit.ly/39EFTB2

Barros, D. L. P. (2003). Dialogismo, polifonia e enunciação. In D. L. P. Barros \& J. L. Fiorin (Orgs.), Dialogismo, polifonia, intertextualidade, (pp. 1-9). São Paulo, SP: Edusp.

Bastidas-Bilbao, H., \& Velásquez, A. M. (2016). Modelo lógico de la supervisión como actividad educativa para la formación en psicología clínica: concepciones de supervisores clínicos. Avances en Psicología Latinoamericana, 34(2), 293-314. Recuperado de https://bit.ly/3319qU6

Boris, G. D. J. B (2008). Versões de sentido: um instrumento fenomenológico-existencial para a supervisão de psicoterapeutas iniciantes. Psicologia Clínica, 20(1), 165-180. Recuperado de https://bit.ly/2EiJyZu

Brait, B. (2005). Bakhtin: conceitos-chave. São Paulo, SP: Contexto.

Buys, R. C. (1987). Supervisão de psicoterapia na abordagem humanista centrada na pessoa. São Paulo, SP: Summus.

Campos, L. F. L. (1999). Avaliação do estilo, personalidade e foco na atuação do supervisor de estágios clínicos.
Revista Estudos de Psicologia, 16(1), 45-61. Recuperado de https://bit.ly/330jWuI

Carvalho, E. P. (2014). Dialogismo e construção de sentidos: os discursos de alunos da educação profissional de jovens e adultos. Cadernos do Instituto de Letras, (48), 6-21. Recuperado de https://bit.ly/3f2tkAj

Falender, C., \& Shafranske, E. P. (2004). Clinical supervision: a competency-based approach. Washington, DC: APA.

Faraco, C. A., \& Shafranske, E. P. (2009). Linguagem e diálogo: as ideias linguísticas do círculo de Bakhtin. São Paulo, SP: Parábola.

Fernandes, L. F. B., Miyazaki, M. C. O. S., \& Silvares, E. F. M. (2015). Caracterização da supervisão em um centro formador de psicologia da saúde. Estudos de Psicologia $I$, 32(3), 499-509. Recuperado de https://bit.ly/3g8nkY8

Josso, M.-C. (2007). A transformação de si a partir da narração de histórias de vida. Revista Educação, 63(3), 413-438. Recuperado de https://bit.ly/2P0BcYG

Marková, I. (2006a). Dialogicidade e representações sociais: as dinâmicas da mente. Petrópolis, RJ: Vozes.

Marková, I. (2006b). On "the inner alter" in dialogue. International Journal for Dialogical Science, 1(1), 125-147. Recuperado de https://bit.ly/3jDVTro

Moreira, S. B. S. (2003). Descrição de algumas variáveis em um procedimento de supervisão de terapia analítica do comportamento. Psicologia: Reflexão e Crítica, 16(1), 157-170. Recuperado de https://bit.ly/30SNEPz 
Oliveira-Monteiro, N. R., \& Nunes, L. T. (2008). Supervisor de psicologia clínica: um professor idealizado? Psico-USF, 13(2), 287-296. Recuperado de https://bit.ly/30UFBSz

Prebianchi, H. B., \& Amatuzzi, M. M. (2000). Análise de uma experiência de supervisão clínica. Revista Estudos de Psicologia, 17(1), 55-63. Recuperado de https://bit.ly/2P0BK0G

Rodrigues, R. R. B. (2007). Estágio supervisionado em psicologia organizacional: estudo preliminar. Série Documental: Relatos de Pesquisa, 3(25), 149-151. Recuperado de

Rommetveit, R. (1976). On the architecture of intersubjectivity. In L. H. Strickland, F. E. Aboud \& K. L. Gergen (Eds.), Social psychology in transition (pp. 201-214). Boston: Springer.

Sá, R. N, Azevedo Junior, O. A, \& Leite, T. L. (2010). Reflexões fenomenológicas sobre a experiência de estágio e supervisão clínica em um serviço de psicologia aplicada universitário. Revista da Abordagem Gestáltica, 16(2), 135-140. Recuperado de https://bit.ly/2WZ6ljw

Saraiva, L. A., \& Nunes, M. L. T. (2007). A supervisão na formação do analista e do psicoterapeuta psicanalítico. Estudos de Psicologia, 12(3), 259-268. Recuperado de https://bit.ly/39z3nHE

Sei, M. B., \& Paiva, M. L. S. C. (2011). Grupo de supervisão em psicologia e a função de holding do supervisor. Psicologia: Ensino \& Formação, 2(1), 9-19.

Severo, C. G. (2007). Por uma aproximação entre Bakhtin e Hannah Arendt. Revista de Ciências Humanas, 41(1-2), 59-81. Recuperado de https://bit.ly/2X0pMso

Silva, N. O. (2019). Considerações acerca da atividade profissional do supervisor clínico em psicologia (dissertação de mestrado), Universidade Federal de Pernambuco, Recife, PE.
Simão, L. (2005). Bildung, culture and self a possible dialogue with Gadamer, Boesch and Valsiner? Theory \& Psychology, 15(4), 549-574. Recuperado de https://bit.ly/2X0ITCy

Simão, L. (2010). Ensaios dialógicos: compartilhamento e diferença nas relações eu-outro. São Paulo, SP: Hucitec.

Sousa, C. R., \& Padovani, R. C. (2015). Supervisão em terapias cognitivo-comportamentais: trilhando outros caminhos além do serviço-escola. Revista Psico-USF, 20(3), 461-470. Recuperado de https://bit.ly/2X1dpfC

Tápias-Oliveira, E. M., Kleiman, A., \& Matencio, M. L. M. (Orgs.). (2005). Letramento e formação do professor: práticas discursivas, representações e construção do saber. Campinas, SP: Mercado de Letras.

Tavora, M. T. (2002). Um modelo de supervisão clínica na formação do estudante de psicologia: a experiência da UFC. Psicologia em Estudo, 7(1), 121-130. Recuperado de https://bit.ly/30U4gXg

Valsiner, J. (1998). The guided mind. Cambridge, MA: Harvard University Press.

Valsiner, J. (2003). Editorial introduction: Beyond intersubjectivity. Culture \& Psychology, 9(3), 187-192.

Valsiner, J., \& Van Der Veer, R. (2000). The social mind: construction of the idea. Cambridge, UK: Cambridge University Press.

Vieira, E. M., Bezerra, E. N., Pinheiro, F. P. H. A., \& Branco, P. C. C. (2018). Versão de sentido na supervisão clínica centrada na pessoa: alteridade, presença e relação terapêutica. Revista Psicologia e Saúde, 10(1), 63-76. Recuperado de https://bit.ly/3hEfYvZ

Recebido: $25 / 04 / 2020$

Aprovado: 20/07/2020 